\title{
The Galileoscope project: community-based technology education in Arizona
}

Stephen Pompea, Leonard Fine, Robert Sparks, Constance Walker, Charles Dugan, et al.

Stephen M. Pompea, Leonard W. Fine, Robert T. Sparks, Constance E. Walker, Charles L. Dugan, Erin F. C. Dokter, "The Galileoscope project: community-based technology education in Arizona," Proc. SPIE 9289, 12th Education and Training in Optics and Photonics Conference, 92892F (17 July 2014); doi: 10.1117/12.2070734

EDent: 12th Education and Training in Optics and Photonics Conference, 2013, Porto, Portugal 


\title{
The Galileoscope Project: Community-Based Technology Education in Arizona
}

\author{
Stephen M. Pompea ${ }^{\mathrm{a}}$, Leonard W. Fine ${ }^{\mathrm{b}}$, Robert T. Sparks ${ }^{\mathrm{a}}$, Constance E. Walker ${ }^{\mathrm{a}}$, Charles L. \\ Dugan $^{\mathrm{a}}$, and Erin F. C. Dokter ${ }^{\mathrm{c}}$ \\ ${ }^{a}$ National Optical Astronomy Observatory, 950 N. Cherry Avenue, Tucson AZ USA 85719 \\ ${ }^{\mathrm{b}}$ Science Foundation Arizona, 400 East Van Buren, Suite 200, Phoenix, Arizona 85004 \\ 'Office of Instruction and Assessment, The University of Arizona, 1500 E. University Boulevard, \\ Tucson AZ USA 85721
}

\begin{abstract}
A program model has been developed and implemented over the last three years to provide a robust optical technologybased science education program to students aged 9-11 years (5th grade), a formative time in the development of a student's interest in science and engineering. We have created well-tested and evaluated teaching kits for the classroom to teach about the basics of image formation and telescopes. In addition we provide professional development to the teachers of these students on principles of optics and on using the teaching kits. The program model is to reach every teacher and every student in a number of mid-sized rural communities across the state of Arizona. The Galileoscope telescope kit is a key part of this program to explore optics and the nature of science. The program grew out of Module 3 of the NSF-Supported Hands-On Optics project (SPIE, OSA, and NOAO) and from the Science Foundation Arizonasupported Hands-On Optics Arizona program. NOAO has conducted this program in Flagstaff, Yuma, Globe, and Safford, Arizona and is being expanded to sites across the entire state of Arizona (295,254 square kilometers). We describe the educational goals, evaluations, and logistical issues connected to the program. In particular, we proposed that this model can be adapted for any rural or urban locations in order to encourage interest in science, astronomy and optics.
\end{abstract}

Keywords: optics education, educational systems, educational reform, technology education, public engagement

\section{INTRODUCTION}

The National Optical Astronomy Observatory (NOAO) played a key role in the International Year of Astronomy 2009 (IYA2009). NOAO and the American Astronomical Society serving as the U.S. coordination bodies of the U.S. effort funded by the National Science Foundation led the development of many of the worldwide cornerstone projects. ${ }^{1}$ Many of these projects directly involved optics and photonic education, as these are key areas in astronomy education. ${ }^{2}$ For example, the IYA2009 Cornerstone project on Dark Skies Education has contributed to a more general approach on teaching about energy conservation and illumination engineering. ${ }^{3}$

For the IYA2009, the U.S. single point of contact and the project director were sited at NOAO [D. Isbell and S. Pompea]. NOAO also led the U.S. working group on "Optics Challenges and Telescope Kits" which was trying to address deficiencies in astronomical telescope kits for children. ${ }^{4}$ The working group also wanted children to have a much broader exposure to optics, and especially geometrical optics and image formation as research has shown that children hold many very persistent misconceptions about optics. ${ }^{5}$ An understanding of these optics misconceptions, which can be established by careful questioning, plays a key role in the approach of optics education programs. ${ }^{6}$

The Galileoscope telescope kit was created for IYA 2009 and widely distributed around the globe. ${ }^{7}$ NOAO designed and ran several experiments on how to integrate the Galileoscope into formal and informal programs. This paper describes a formal education program designed to serve Arizona schools, teachers, and students. Previous efforts, such as the national Hands-On Optics program ${ }^{89}$ (funded by the National Science Foundation) and the Hands-On Optics Arizona

12th Education and Training in Optics and Photonics Conference, edited by

Manuel F. P. C. Martins Costa, Mourad Zghal, Proc. of SPIE Vol. 9289, 92892F

(c) 2014 SPIE, OSA, IEEE, ICO · doi: 10.1117/12.2070734

Proc. of SPIE Vol. 9289 92892F-1 
project, funded by Science Foundation Arizona, had addressed informal education in optics through ten programs at rural Boys and Girls Clubs throughout the state. The effort described in this paper is a small part of a much larger effort started by Science Foundation Arizona to improve Science, Technology, Engineering, and Mathematics (STEM) education throughout Arizona, including the largely rural areas. ${ }^{10}$

In 2008, a report by the Arizona Department of Commerce Aerospace and Defense Committee ${ }^{11}$ described how the economic future of the state of Arizona depends on the development of a highly technologically skilled workforce as well as a strong community college and university system. However, this same report was concerned with the quality of the education provided in Arizona's public school system. Since 2008 when the report was written, the educational system in Arizona has been under increasing stress with little additional money made available for school improvement programs.

To supplement and reinforce science programs in the schools, and especially in rural Arizona, the National Optical Astronomy Observatory and Science Foundation Arizona created the Arizona Galileoscope Project. The project has two components: professional development of teachers on the optics and the student work with the Galileoscope. These two components are combined to enable a strong community based program for elementary or primary school students.

\section{PROGRAM DESIGN}

The Arizona Galileoscope program has a robust model that we have implemented and refined in a number of Arizona's cities. The program was created as an efficient supplemental program that augments what is being done in $5^{\text {th }}$ grade in Arizona schools. The $5^{\text {th }}$ grade curriculum covers the solar system studies and is also an appropriate time for optics and technology exploration. Our program lasts about half a school year in each location and is designed to be repeated each year for at least three years. Our program has as its major components:

- Selection: Communities express interest in the program and make a commitment to the program after learning more about it and having their questions and concerns answered. Usually this involves a meeting with school leaders including the school district superintendent, lead teacher, and science coordinators. The program tries to target an entire city or school district. We have decided that $5^{\text {th }}$ grade students are our ideal target audience. We have been focusing on communities with between 15 and $255^{\text {th }}$ grade teachers. This number of teachers provides a workable size audience for professional development. It is likely that this component of the program will change as we move the program to larger or smaller cities.

- Teacher Professional Development: Teachers receive training on concepts involving optics and the nature of light and color as well as training on the Galileoscope. Our program is based on the Hands-On Optics project training for afterschool and museum educators. It strives to improve the subject matter knowledge of the teacher and to address the teaching pedagogy related to optics education. We have designed a special kit for teachers with all of the materials that they will need to teach the relevant material. The kit is a classroom-ready set of literature and resources for teachers.

- Classroom Activities: Teachers conduct optics activities and lessons with their students. These students learn optics concepts through a variety of experiments and activities that can be done in class with their teachers.

- Telescope Building: After some basic introductions to refraction and image formation, the $5^{\text {th }}$ grade classes then build the Galileoscopes and learn the parts of a telescope and their function as part of the building process.

- Telescope Operation: The classes then learn how to properly mount the Galileoscopes on a tripod and to point the telescopes during the daytime. Suitable objects include trees, fences, and buildings at first. Then the students learn how to point the telescope at objects that are closer to the zenith. Since this is done during the day, great care must be taken to avoid creating the possibility of looking at the Sun.

- Star Party Preparation: Preparations are made for the star party, including identifying the moon when possible, the main planets visible and some of the brighter double stars, star clusters, and emission nebulae. At certain times of the year, the Andromeda galaxy can be seen and is an appropriate object.

- The Star Party: The large star party is held. It may have hundreds of $5^{\text {th }}$ graders and their families. The teacher is expected to do follow up work with their students after the star party.

- Post Star Party: The teacher may do follow up work with the students to reinforce the optics and astronomy lessons. The Galileoscopes may be loaned to students for home observations. 
These stages last approximately one semester of a school year and require intensive involvement from NOAO EPO staff skilled in professional development visiting the classrooms and working with students using the Galileoscope.

\section{ABOUT THE GALILEOSCOPE}

The Galileoscope itself is the primary tool of the program and the motivation for the teachers and students participating in the program. Each teacher receives a classroom set of Galileoscopes and tripods. Typically there is on telescope-tripod for each three students, so students work in collaborative groups to build and use the telescope. The telescope is durable and has a 50-mm objective lens that yields 25-power with a high quality eyepiece. The telescope gives excellent views of planets, the Moon, star clusters like the Pleiades-the objects that Galileo observed over 400 years ago. The Galileoscope, designed with city use in mind, was tested in large cities with bright lights. As part of the International Year of Astronomy, the Galileoscope was also part of the first White House Star party held on October 7, 2009. ${ }^{2}$

A key feature of the Galileoscope is that it is very durable and does not require any adhesive in its assembly and does not have any tabs, snaps, or pieces that can eventually break. Thus it can be assembled and taken apart many times. This makes it ideal for use in multiple classes over many years. The initial investment in buying Galileoscopes (www. galileoscope.org) is a non-recurring program cost.
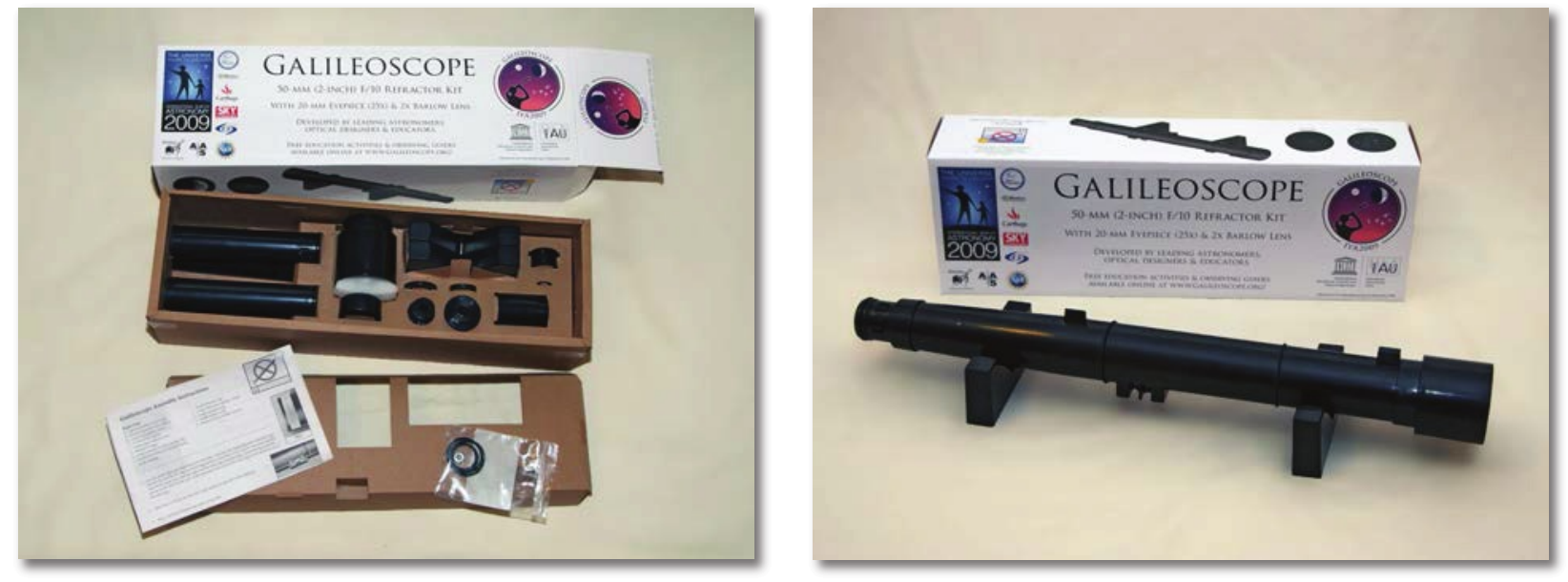

Figure 1: Left: The Galileoscope telescope kit. The telescope can be assembled in approximately one hour. The telescope can be assembled and disassembled without tools, and is durable enough for long-term classroom use. Right: Assembled Galileoscope, on its plastic display stand. The telescope can be used as an optical experimentation bench when partially assembled.

\section{PROFESSIONAL DEVELOPMENT FOR TEACHERS}

The professional development program offered for teachers in a city or school district is meant to be responsive to the teachers needs. If the teachers have time, a more extensive workshop can be arranged. However, generally, a one-day workshop is all that time will allow. In some districts this workshop might be repeated to train any teachers who were absent from the first workshop. A longer, two-day workshop would be highly desirable from a professional development perspective. In practice it is quite difficult for teachers to find time to participate in a longer workshop due to the very large demands on their time. During this professional development day, NOAO conducts activities that cover the basics 
of refraction, forming images using one or two lenses, and the basic properties of a telescope. These activities were originally part of Module 3 of the Hands-On Optics program. The Module 3 activities include:

1. Refraction of Light Through an Acrylic Block

2. Light Passing Through a Convex Lens

3. Finding Lens Focal Lengths Using a Distant Object

4. Simple Magnifiers

5. Experiments in Arranging Lenses

6. Refracting Telescope: Functions of the Eyepiece

7. Measuring Resolution and Other Properties

The workshop is designed to be as inquiry-oriented and participatory as possible. Other aspects of the workshop include how to build and use a Galileoscope, how to run a star party, and the basic observing of astronomical objects. A workshop for classroom teachers must establish the links from the optics activities to the Common Core Standards, the national science education standards, the national technology education standards, and the National Council of Teachers of Mathematics standards. In the near future, the activities will be linked to the Next Generation Science Standards. ${ }^{13}$

To support their activities,, each teacher receives a teacher's guide, which includes a glossary, a list of optics misconceptions, basic lesson plans, and an accompanying observing guide to astronomical objects visible throughout the year. The Galileoscope Optics Teaching Guide and the Galileoscope Observing Guide are available in pdf format. Most of the supporting materials can be downloaded from www.teachingwithtelescopes.org, the support web site for educators. The "Teaching with Telescopes" project is an NOAO core-funded project to support teaching with small telescopes, established as an effective way to excite children about science.

\section{THE GALILEOSCOPE CLASSROOM TEACHING KIT}

The professional development workshop is successful because it encourages teachers and develops their confidence in teaching optics. A part of this support effort is to give the teachers the proper materials that can serve their entire class. We encourage the teachers in the workshop to start teaching with the materials as soon as they can. We also encourage teachers to emphasize collaborative learning and problem solving. This emphasis on experimentation is at the heart of science education, and has proven to be an effective approach. ${ }^{14}$ In this sense, the Galileoscope is a tool for exploration and experimentation and the night sky is our laboratory.

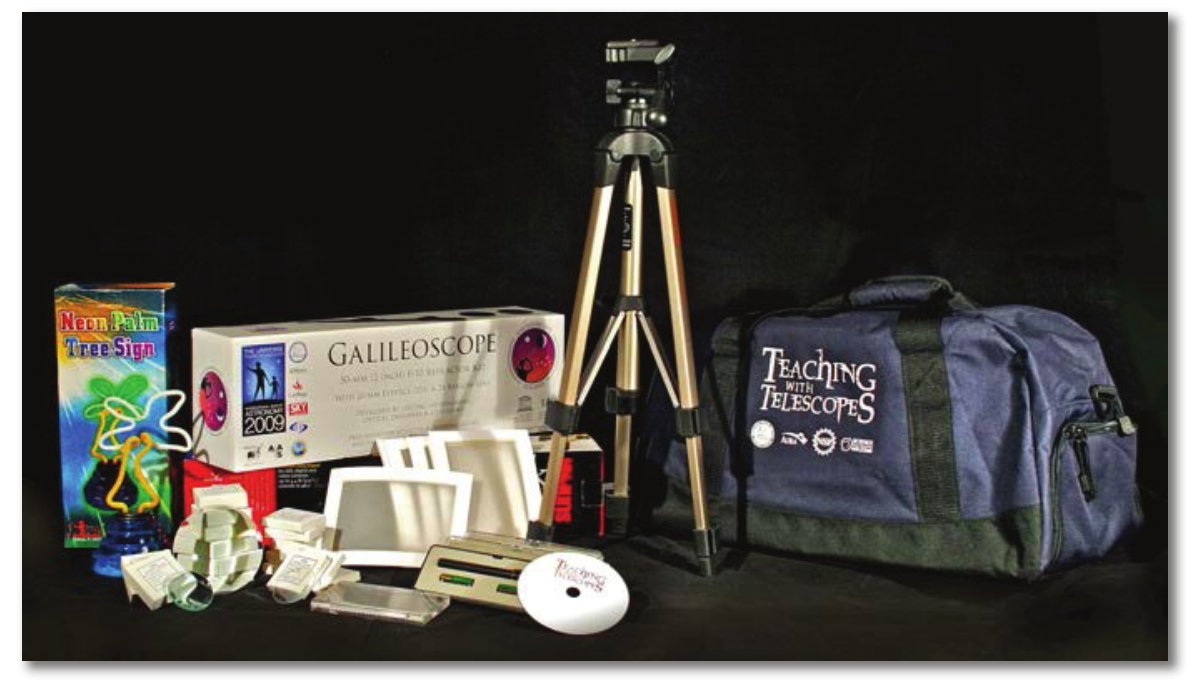

Figure 2: The Galileoscope classroom kit that teachers receive as part of their professional development workshop. 
The "Teaching with Telescopes" kit includes

- Two Galileoscope classroom telescopes

- Two high quality tripods

- Classroom set of lenses of short and long focal lengths

- Large double convex demonstration lens

- Demonstration lasers

- Lucite block that can be used to demonstrate refraction

- Vellum screens

- An asymmetrical colored light source

- DVD of printable classroom activities

This kit is a less expensive version of the Hands-On Optics Module 3 teaching kit, developed at NOAO with assistance from the Optical Society of America and SPIE.

\section{THE STAR PARTY}

The star party is designed as the culminating activity of the program. As such it also serves as a form of authentic assessment. The students have experimented with refraction and image formation, have built and learned how to use the Galileoscope, and now will use the telescope to make astronomical observations. The final star party is an opportunity for the students to apply their knowledge and to start exploring the night sky. A key part of the preparation for the star party is practice in aiming the Galileoscopes. The tripods are of adequate quality but some practice is needed in aiming the telescopes at celestial objects. This is best achieved by using the telescopes during the day to look at objects at a variety of azimuths and angles. As students gain skill using the tripod and pointing the telescopes during the day, their performance at night increases tremendously. A rule of thumb for star parties is to have the telescopes set up before it gets dark. Ideally, the Moon can be observed first and can be used to aid in reminding students how to adjust the tripod, point the telescope, and adjust focus.
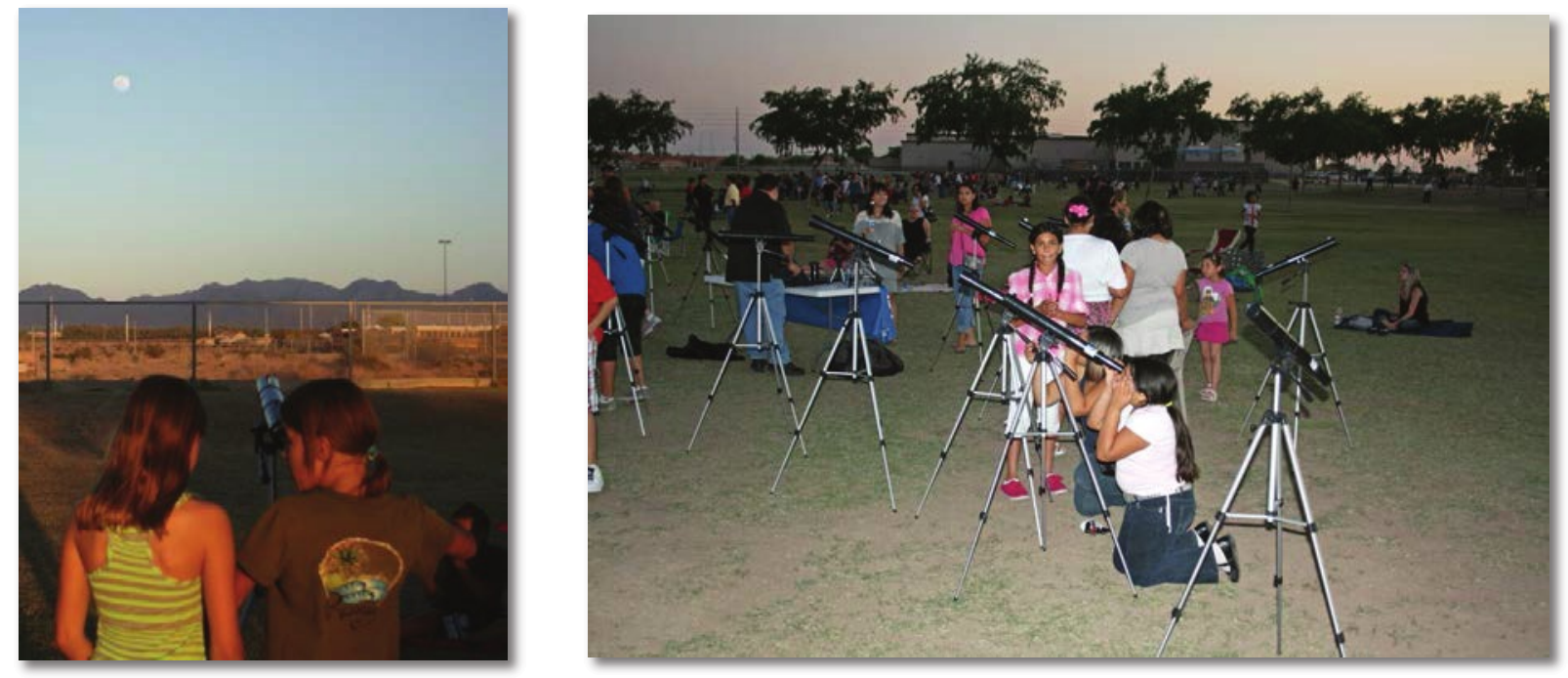

Figure 3: Left: Yuma, Arizona $5^{\text {th }}$ grade students prepare to observe the Moon. Right: Group of students and their families using the Galileoscope at the Yuma Star Party, which had hundreds of attendees.

These star parties are community-wide events where families, neighbors, and friends are invited to observe with the Galileoscopes. Local amateur astronomers also bring a few telescopes to observe fainter objects. The typical program only lasts 2-3 hours, allowing younger children (who often get cold easily or cannot stay up late) to attend. Most star parties are scheduled on Friday nights. The location ideally is a place that all of the students and their parents know. It 
does not need to be a very dark location or far from town. It should be a convenient venue where streetlights can be turned off or are not intrusive. Schoolyards or parks seem to be ideal as they provide large parking areas in close proximity, they have large fenced areas, and they have restroom facilities for large groups.

Science Foundation Arizona has been a partner in the program from its inception. Figure 4 shows the location of the star party programs in Arizona, to date. The first star party was held at the Arizona state capitol complex in Phoenix as a

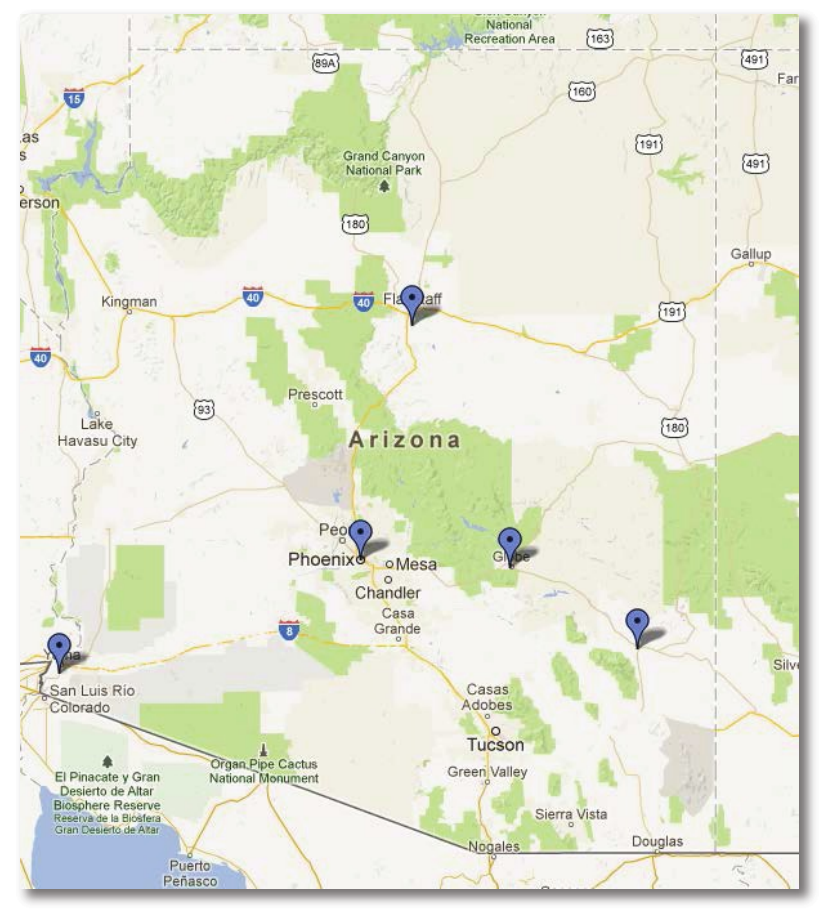
proof of concept. No star party program is currently in place in Phoenix as the program has concentrated on rural areas.

The star parties begin with an introduction by school officials and have a set timetable. The areas where the telescopes need to be set up should be clearly delineated. Students receive a list of telescopic objects that they can observe and stickers to place on their telescope after they observe them. At the end of the evening the observing sheets or tickets can be used for a prize drawing. Generally, several Galileoscopes and binoculars plus some DVDs are used for prizes. When the weather is cold, it is important to prepare the families by encouraging them to dress warmly. Prolonging a star party is also not useful educationally as everyone gets tired. In some of our rural locations, the families may have to drive an hour to attend the star party.

The key to a good star party is the preparation of the students and site logistics. Also key is having enough people to help students with any telescope problems and to help them locate the more difficult objects.

Figure 4: This map describes where this Galileoscope program is situated. Programs have been held in Yuma (southwest Arizona), Safford (southeastern Arizona). Flagstaff (north central Arizona), and Globe (south central Arizona). Future programs are planned for other areas of the state such as couth central and northwestern Arizona.

It is critically important to establish a "weather call protocol". What will happen if bad weather forces cancellation? Is there an indoor facility to move to? Is there a "fallback date" established? Who is the responsible individual that will make the final call, what time will this happen, and how will the teachers and classes be informed? These issues must be coordinated when the final star party date is chosen so all parties are aware of the contingencies.

It is often very helpful for the star party to be organized by classes. Each teacher is then responsible for his or her own class; often the teachers know the families well. Families are encouraged to bring food, warm clothing and blankets, and chairs to increase their enjoyment of the evening. They can also bring binoculars, flashlights, and even telescopes. Some schools use this opportunity to sell food, snacks, and warm drinks to earn revenue for Parent-Teacher-Organizations, or classroom or school clubs.

As of June, 2011, the program has been used in Yuma for three years, Flagstaff for two years, Safford for two years, and Globe for one year. A prototype star party was held in Phoenix the first year to initiate the program. The program has reached 3,000 fifth grade students. Future sites may include additional communities in southern, northwestern, and southeastern Arizona.

\section{PROGRAM EVALUATION}

Evaluation is an important part of our program and is part of our program for continuous quality improvement. The program components previously described have been evaluated to assess the professional development training. NOAO staff visits to classrooms, and star parties. The evaluation collected data from observations at schools and the professional development workshop, from interviews with and surveys from teachers, and in interviews with parents and 
students, as well as school officials. The evaluator was also present at many of the culminating star parties. The results of these evaluations show that the stakeholders in the program had a very positive response to the professional development provided and to the community outreach that it afforded. The professional development program was reported to be of high-quality by participating teachers, principals, and other school district officials.

Some of the key issues identified by the evaluation describe the importance of careful planning with participating schools and communities, the need for extended time for teachers to build Galileoscopes with their students and the importance of checking the build of the eyepieces.

Attendance at star parties was high. For example, there were 480, 550, and 375 people in attendance at the peak of the star parties in Flagstaff, Yuma, and Safford, Arizona, respectively. Overall, students demonstrated at the star parties that they were able to successfully use the Galileoscopes that they had built to observe astronomical and terrestrial objects. Each star party created a great deal of excitement when students saw Jupiter and its Galilean satellites, the rings of Saturn, or craters on the Moon.

There was also a general feeling the star party brought the community together and was a great opportunity for students to show off their work and even to teach their parents and siblings about astronomy. In general, the program was observed to be a successful, well-planned program that met the extended needs of teachers, students, schools, and communities. The NOAO staff was widely praised for their sensitivity to educational issues and their excellent and extensive planning.

\section{CONCLUSION}

The NOAO/Science Foundation Arizona Galileoscope Program in Arizona represents a highly effective program and program model that supplements science education in $5^{\text {th }}$ grade classrooms. It is effective in introducing key optics concepts into primary schools. The evaluation indicates that this model may be applicable for other states. In the future, the program will expand to other cities in Arizona.

\section{Acknowledgements}

The National Optical Astronomy Observatory is operated by the Association of Universities for Research in Astronomy (AURA), Inc. under a cooperative agreement with the National Science Foundation. The Arizona Galileoscope Project is also supported by Science Foundation Arizona.

\section{REFERENCES}

\footnotetext{
1 Pompea, S. M., Schweitzer, A., Deustua, S., Isbell, D., Fienberg, R. T., Arion, D. N., Walker, C. E., Gay, P. L., Smith, D., Pantoja, C. A., Watzkem, M., and Arcand, K., “International Year of Astronomy 2009 Cornerstone Projects: What's Available for You", Science Education and Outreach: Forging a Path to the Future, eds. J. Barnes, D. Smith, M. Gibbs, and J. Manning, ASP Conference Series Volume 431 (2010).

2 Walker, C. E., Sparks, R. T., and. Pompea, S. M, "Optics Education in the International Year of Astronomy," in Proceedings Education and Training in Optics and Photonics (2007).

3 Walker, C. E. and Pompea, S. M., "National Education Program for Energy Efficient Illumination Engineering, Proceedings SPIE: Eco-Photonics 2011: Sustainable Design, Manufacturing, and Engineering Workforce Education for a Green Future, March 29, Strasbourg, France (2011)

4 Pompea, S. M., Fienberg, R., Deustua, S., and Isbell, D., "Telescope Kits \& Optics Challenges for the International Year of Astronomy 2009 ”, [Education and Public Outreach - A Changing World: Creating Linkages and Expanding Partnerships], Astronomical Society of the Pacific Conference Series 389, eds. C. Garmany, M.G. Gibbs, J.W. Moody, (2008)

5 Pompea, S. M., Dokter, E. F., Walker, C. E., and Sparks, R. T., "Using Misconceptions Research in the Design of Optics Instructional Materials and Teacher Professional Development Programs", Proceedings Education and Training in Optics and Photonics 2007, Ottawa, Canada, (2007).

6 Dokter, E. F. C., Pompea, S. M., Sparks, R. T., Walker, C. E. “The Development of Formative Assessment Probes for Optics Education”, Proceedings SPIE: Optics Education and Outreach, Vol. 7783, (2010).

7 Pompea, S. M., Pfisterer, R. N., Ellis, K. S., Arion, D. N., Fienberg, R. T., “Optical and System Engineering in the Development of a High-Quality Student Telescope Kit”, Proc. SPIE: Modeling, Systems Engineering, and Project Management for Astronomy IV (2010).

8 Pompea, S. M., Walker, C. E., and Sparks, R. T. "Knowledge and Wonder: Engagements with Light and Color in the Hands-On Optics Project," in Exemplary Science in Informal Education Settings: Standards-Based Success Stories, edited by R. Yager and J. Falk, 47-70, NSTA Press (2008)
} 
9 Pompea, S. M., Johnson, A., Arthurs E. and Walker, C. E, "Hands-On Optics: An Educational Initiative for Exploring Light and Color in After-School Programs, Museums, and Hands-On Science Centers", Proc. Ninth International Topical Meeting on Education and Training in Optics and Photonics, Marseille, France (2005).

10 Pompea, S. M., Fine, L. W., and Meystre, P., "Photonics Education for a Green Future: Connecting the Dots of the Arizona STEM Education Experiment, Proceedings SPIE: Eco-Photonics 2011: Sustainable Design, Manufacturing, and Engineering Workforce Education for a Green Future, March 29, 2011, Strasbourg, France (2011).

11 Aerospace and Defense Commission's Annual Reports, 2008 Commission Report at http://www.azcommerce.com/Councils/ad_reports.htm

12 www.aura-astronomy.org/nv/Astronomy\%20Beat-WHSP.pdf

13 Achieve, Inc. on behalf of the twenty-six states and partners that collaborated on the NGSS, Next Generation Science Standards, Achieve, Inc. on behalf of the twenty-six states and partners that collaborated on the NGSS (2013).

14 Lazarowitz, R. and Tamir, P., "Research on Using Laboratory Instruction in Science, in [Handbook of Research on Science Teaching and Learning], edited by D. L. Gabel, Macmillan, (1994).

Proc. of SPIE Vol. 9289 92892F-8 